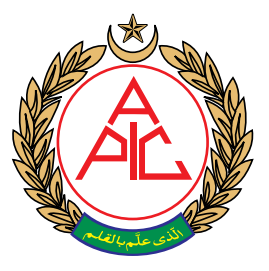

${ }^{1}$ Department of Anesthesiology, Max Smart Super Specialty Hospital, Delhi, India.

${ }^{2}$ Department of Anesthesiology, Temple University Hospital, Philadelphia, USA.

Correspondence: Dr Mukul Chandra Kapoor 6-Dayanand Vihar, Delhi 110092 (India)

Tele: $+91-9971888773$

Fax: +91-11-26963801

E-mail: mukulanjali@gmail.com; Mukul.Kapoor@maxhealthcare. com

Received: 11 June 2019; Reviewed: 20, 23 October 2019; Revised: 31 January 2020; Second Review: 2, 7 January 2020;

Accepted: 02 February 2020

\section{I-gel supraglottic airway use is efficient and safe during minimal flow anesthesia with volume controlled ventilation - a randomized controlled trial}

\author{
Asma Khan, MD ${ }^{1}$, Mukul Chandra Kapoor, MD, DNB ${ }^{1}$, Shaloo Garg, \\ $\mathrm{MD}, \mathrm{DNB}^{1}$, Archana Puri, $\mathrm{MD}^{1}$, Ashish Sinha, MD, PhD, MBA ${ }^{2}$
}

\section{ABSTRACT}

Background: A fear of potential gas leak limits the wide spread use of minimal flow anesthesia with supraglottic airway devices. Second generation supraglottic airway devices have been claimed to be come with good airway seal. I-gel is one of these and it has been extensively evaluated for spontaneous as well as assisted ventilation. We conducted this study to evaluate its use with low flow anesthesia and volume controlled ventilation.

\begin{abstract}
Methodology: In a prospective randomized controlled trial, 50 patients undergoing laparoscopic surgeries for less than $2 \mathrm{~h}$ duration were administered general anesthesia, with controlled ventilation, using either endotracheal tube or an I-gel for airway control. The total fresh gas flow was gradually reduced until it was $400 \mathrm{~mL} / \mathrm{min}$. Patients were monitored for evidence of loss of respiratory gas volume in the breathing circuit and other parameters for ventilation failure.
\end{abstract}

Results: Ventilation could be maintained at a fresh gas flow of $400 \mathrm{~mL} / \mathrm{min}$, without clinical or volumetric evidence of gas leak in all patients in the two groups. Two patients in the I-gel group had intraoperative gas leak leading to ventilator failure alarm but the same was corrected by repositioning of the head. The vital signs, peak airway pressure, end-tidal carbon dioxide, set tidal volume and expired tidal volumes were statistically similar in the two groups.

Conclusion: I-gel supraglottic airway can be safely and efficiently used for laparoscopic surgery using minimal flow anesthesia and volume controlled ventilation.

Key words: Supraglottic airway device; I-gel; Minimal flow anesthesia.

Abbreviations: Supraglottic airway device - SAD; Volume controlled ventilation - VCV; Pressure controlled ventilation - PCV; Endotracheal tube - ETT; Laryngeal Mask Airway - LMA

Citation: Khan A, Kapoor MC, Garg S, Puri A, Sinha A. I-gel supraglottic airway use is efficient and safe during minimal flow anesthesia with volume controlled ventilation-a randomized controlled trial. Anaesth pain intensive care 2020;24(1):36-41. DOI: https://doi.org/10.35975/apic.v24i1.1219

\section{INTRODUCTION}

Airway management has become less invasive with the introduction of supraglottic airway devices
(SAD). A survey on usage of SADs in 11,910 patients demonstrated their safety and efficacy for gynecologic laparoscopy, gynecologic laparotomy and other procedures of $>2 \mathrm{~h}$ duration, during spontaneous 
as well as controlled ventilation. ${ }^{1}$ Specialized second generation SADs, such as Proseal and I-gel, have become popular for laparoscopic surgeries as good airway seal can be achieved with them. ${ }^{2,3}$ However, SAD are less commonly used for low flow anesthesia as poor glottic fit and leak can compromise gas exchange. The use of SAD to deliver low flow and minimal flow anesthesia has been restricted to anesthesiologists experienced with their use and with the use of minimal flow anesthesia. ${ }^{4}$ This study was formulated to show the safety and efficacy of I-gel (Intersurgical Ltd, Berkshire, UK) use during minimal flow anesthesia with volume controlled ventilation (VCV) for laparoscopic surgery of $<2 \mathrm{~h}$ duration.

\section{METHODOLOGY}

After approval from institutional ethics committee, a prospective, interventional, blinded, randomized controlled trial was conducted on 50 American Society of Anesthesiologists grade 1-3 patients, undergoing laparoscopic surgeries (Table 1) lasting $<2 \mathrm{~h}$. The trial was registered with Controlled Trial Registry India with ID CTRI/2015/06/009163.

Patients undergoing concomitant procedures; with pulmonary disease; hypersensitivity to one or more medications; previous thoracic surgery; increased risk of aspiration; morbid obesity; and anticipated difficult airway were excluded. On enrolment, written informed consent was obtained from all participants.

The sample size was estimated considering a mean difference of 0.25 between the two groups as clinically significant, based on the study by Uppal et al. comparing I-gel with endotracheal tube (ETT) using pressure controlled ventilation (PCV). ${ }^{2}$ For a standard deviation value of 0.05 , using a power of $80 \%$ and significance value of 0.05 for a two-sample t-test comparing two groups, a total of 25 patients per group were needed. Patients were allocated into two groups, I-gel group and ETT group, by computer-generated randomization. All patients were subjected to routine preoperative assessment and fasting protocol. A standardized general anesthesia induction protocol was followed, comprising of fentanyl $1-2 \mathrm{mcg} / \mathrm{kg}$ intravenous (IV) and propofol $1.5-2 \mathrm{mg} / \mathrm{kg}$ IV. The airway was secured by an appropriate size ETT or I-gel after administration of atracurium. I-gel size was selected in accordance with manufacturer's guidelines $(<50 \mathrm{~kg}$ : I-gel size $3 ; 50-70 \mathrm{~kg}$ : size 4 ; and $>70 \mathrm{~kg}$ : size 5). All airway interventions were performed by a single user, who had experience of over 500 I-gel insertions. Appropriate placement of I-gel was confirmed by observing an end-tidal $\mathrm{CO}_{2}$ $\left(\mathrm{EtCO}_{2}\right)$ waveform and movements of the chest wall. Orogastric tube was passed through the gastric tube channel in all cases in the I-gel group. The head end of the patient was then covered by a sheet for the purpose of blinding of the next anesthetist who was the designated observer of ventilator parameters.

Anesthesia was maintained with desflurane in oxygen and nitrous oxide titrated to maintain $\mathrm{FiO}_{2}$ of 0.5 (based on inspired oxygen monitoring at the patient end). A Drager Fabius Plus anesthesia delivery system (Dräger Medizintechnik GmbH, Lübeck, Germany) was used in all cases. Intraoperative monitoring consisted of heart rate, electrocardiography, pulse oximetry, $\mathrm{EtCO}_{2}$, temperature and non-invasive blood pressure. VCV, using a semi-closed circle breathing system, was delivered to all patients with the tidal volume set as $6-8 \mathrm{~mL} / \mathrm{kg}$; respiratory rate to maintain $\mathrm{EtCO}_{2}$ between $30-40 \mathrm{mmHg}$; inspiratory-expiratory ratio of 1:2; no peak end-expiratory pressure; and a pressure limit of $30 \mathrm{cmH} 2 \mathrm{O}$.

A total fresh gas flow (FGF) of $6 \mathrm{~L} / \mathrm{min}$ was used until the target expired desflurane concentration (MAC 0.8) was achieved. In both groups, FGF was then reduced to $1 \mathrm{~L} / \mathrm{min}$. FGF was thereafter reduced by $100 \mathrm{~mL} / \mathrm{min}$ till the total $\mathrm{FGF}$ was limited to $400 \mathrm{~mL} / \mathrm{min}$ or till there was no ventilation failure alarm or desaturation. The FGF was not reduced, under any circumstance, to less than $400 \mathrm{~mL} / \mathrm{min}$ for safety reasons. The primary objective was to establish minimum adequate FGF in the breathing circuit with no failure to adequately ventilate the lungs. To determine the primary outcome, the set tidal volume, expired tidal volume, airway pressure and total FGF delivered, apart from the routine parameters, were recorded every minute till reduction of FGF to 400 $\mathrm{mL} / \mathrm{min}$. Thereafter all parameters were recorded every $15 \mathrm{~min}$. The operating surgeon was asked to visually check for gastric distention during surgery.

At the end of the procedure, neuromuscular blockade was reversed and the airway device was removed. Patients were followed up for $24 \mathrm{~h}$ after surgery for secondary outcomes related to the use of the device i.e. complaints of sore throat, dysphagia, sore jaw, dysphonia, numbness of tongue or oropharynx, blocked or painful ears, reduced hearing or neck pain.

Statistical analysis: Statistical analysis was done with MedCalc (version 16.1; www.medcalc.org). Data were reported as mean \pm SD. Analysis of data between the groups was done by Student's t-test for independent samples. For categorical values, Chisquare test was applied. A $p$ value of less than 0.05 was considered statistically significant.

\section{RESULTS}

All 50 enrolled patients completed the study. Both groups were comparable in terms of age, height, weight, and demographics (Table 2). Patients were positioned the two groups as per requirements of the 
Table I: Comparative surgical procedures in the groups

\begin{tabular}{l|c|c}
\multicolumn{1}{c|}{ Surgery } & $\begin{array}{c}\text { ET Group } \\
\mathbf{n = 2 5}\end{array}$ & $\begin{array}{c}\text { I-gel Group } \\
\mathbf{n = 2 5}\end{array}$ \\
\hline Laparoscopic cholecystectomy & 14 & 14 \\
\hline Laparoscopic hernioplasty & 4 & 6 \\
\hline Laparoscopic appendectomy & 1 & - \\
\hline Laparoscopic hiatus hernia repair & 1 & - \\
\hline Laparoscopic ovarian surgery & 1 & 1 \\
\hline Diagnostic laparoscopy \& hysteroscopy & - & 2 \\
\hline Total laparoscopic hysterectomy & - & 2 \\
\hline Laparoscopic myomectomy & 4 & - \\
\hline
\end{tabular}

Table 2: Demographic data

\begin{tabular}{l|c|c|c}
\multicolumn{1}{c|}{ Parameters } & $\begin{array}{c}\text { ET Group } \\
\mathbf{n = 2 5}\end{array}$ & $\begin{array}{c}\text { I-gel group } \\
\mathbf{n = 2 5}\end{array}$ & p-value \\
\hline Age $(\mathrm{y})$ & $48.80 \pm 13.64$ & $49.08 \pm 14.96$ & 0.95 \\
\hline Weight $(\mathrm{Kg})$ & $67.252 \pm 14.40$ & $68.50 \pm 13.93$ & 0.82 \\
\hline Height $(\mathrm{cm})$ & $160.48 \pm 7.06$ & $161.58 \pm 8.55$ & 0.62 \\
\hline Gender Male/Female & $8 / 17$ & $7 / 18$ & 0.76 \\
\hline Duration of surgery (min) & $77.5 \pm 43.79$ & $59.09 \pm 34.07$ & 0.089 \\
\hline Trendelenburg Position (n) & 10 & 11 & \\
\hline Reverse Trendelenburg Position (n) & 15 & 14 & \\
\hline
\end{tabular}

Table 3: Study data

\begin{tabular}{l|c|c|c}
\multicolumn{1}{c|}{ Parameters } & $\begin{array}{c}\text { ET Group } \\
\mathbf{n = 2 5}\end{array}$ & $\begin{array}{c}\text { I-gel group } \\
\mathbf{n = 2 5}\end{array}$ & $\begin{array}{c}\text { p- } \\
\text { value }\end{array}$ \\
\hline Heart rate $(\mathrm{bpm})$ & $76.09 \pm 2.20$ & $70.34 \pm 6.15$ & 0.001 \\
\hline Systolic blood pressure $(\mathrm{mmHg})$ & $125.59 \pm 11.34$ & $115.04 \pm 11.47$ & 0.0122 \\
\hline Diastolic blood pressure $(\mathrm{mmHg})$ & $75.17 \pm 6.09$ & $73.52 \pm 10.05$ & 0.5699 \\
\hline Peak airway pressure $\left(\mathrm{cmH}_{2} 0\right)$ & $24.84 \pm 5.02$ & $22.00 \pm 3.86$ & 0.0837 \\
\hline End-tidal carbon dioxide $\left(\mathrm{mmHg}^{\prime}\right)$ & $32.03 \pm 0.299$ & $32.52 \pm 1.80$ & 0.2909 \\
\hline Set tidal volume $(\mathrm{mL})$ & $480 \pm 28.87$ & $493.2 \pm 22.12$ & 0.0758 \\
\hline Expired tidal volume $(\mathrm{mL})$ & $505.73 \pm 28.16$ & $496.50 \pm 25.29$ & 0.2509 \\
\hline
\end{tabular}

the two groups were statistically similar (Table 3). The duration of surgery was longer in the ETT group than in the I-gel group $(77.5$ $\pm 43.79 \mathrm{~min}$ vs $59.09 \pm 34.07$ min) but the difference did not approach statistical significance $(\mathrm{p}=0.089)$. Ventilation could be maintained at an FGF of 400 $\mathrm{mL} / \mathrm{min}$, without clinical or volumetric evidence of a gas leak, in all patients. Two patients in the I-gel group had intraoperative gas leak leading to ventilator failure alarm. However, repositioning of the head corrected the leak. Gastric distention was not reported in any patient by the operating surgeons. There were no cases of regurgitation or gastric aspiration during the intraoperative period. During the postoperative period, two patients from ETT group complained of sore throat and one patient in the I-gel group complained of difficulty in swallowing. No other complication was noted in either group.

\section{DISCUSSION}

High FGF techniques have been the mainstay of anesthesia practice for several years. In 1952, Foldes described the use of $1 \mathrm{~L} / \mathrm{min}$ FGF in closed breathing systems. ${ }^{5}$ In 1974, Virtue validated his findings and used an even lower FGF of 500 $\mathrm{mL} / \mathrm{min}^{6}{ }^{6}$ The advent of better anesthesia delivery technology has permitted delivery of low and minimal FGF, with a good margin of safety, as breathing systems are leak free. Traditionally ETTs have been used for low and minimal

surgery. 10 patients in ETT group and 11 patients in the I-gel group were placed in Trendelenburg position during surgery, while the remaining patients were placed in reverse Trendelenburg position for surgery (Table 2). The systolic/diastolic blood pressure, peak airway pressures and $\mathrm{EtCO}_{2}$ were statistically comparable in the two groups. There was a statistically significant difference in the mean heart rates in the two groups but as the study objectives were unrelated to hemodynamics and the difference was not clinically significant, the two groups were considered similar. Set and expired tidal volume in flow anesthesia, however, SADs provide as efficient a gas-seal as ETTs and can thus be used in operating rooms without causing pollution. ${ }^{7}$ Since, halogenated inhalational anesthetic agents can catalyze the breakdown of ozone, use of low flow anesthesia and avoiding high FGF can protect the ecology by emitting smaller amounts of ozone-depleting and heat-trapping greenhouse gases. ${ }^{8,9}$

Rebreathing of gases in closed breathing systems prevents loss of heat, drying of mucous membrane, lower rate of airway inflammation/infection and 
reduces inhalational anesthetic agent consumption by more than $75 \% .^{10,11}$ After the saturation point is met, uptake of anesthetic from alveoli is reduced and the agent in the excess gases is vented out. ${ }^{12}$ Minimal flow anesthesia helps reduce wastage by limited addition of respiratory and anesthetic gases into the circuit, thus balancing uptake. Although SADs do not provide watertight seal, Laryngeal Mask Airway (LMA) has been shown to provide as efficient a seal as ETT with reduced loss of anesthetic gas from the closed circuit. ${ }^{13,14}$ Honemann et al (2013) found that LMA and ETT could be used at FGF of $0.5 \mathrm{~L} / \mathrm{min}$ in $84.7 \%$ and $98.3 \%$ of cases respectively. However, in their study, airway leaks did not permit any reduction in FGF in three patients with LMA (3.3\%). ${ }^{15}$ LMA has been compared with cuffed ETT in children during PC ventilation and found to be efficient even at an FGF of $0.2 \mathrm{~L} / \mathrm{min} .{ }^{16}$ Airway sealing pressures with I-gel have been reported to vary between 25 $\mathrm{cm} \mathrm{H} 2 \mathrm{O}$ and $30 \mathrm{~cm} \mathrm{H} 2 \mathrm{O} \cdot{ }^{17,18}$ Although the safety of I-gel during gynecological laparoscopic surgeries has been demonstrated, the leak was reported to be greater in the Trendelenburg position. ${ }^{19}$ Use of SAD during low and minimal flow anesthesia with controlled ventilation has been shown by others to be safe in Trendelenburg position..$^{1,4,20}$ The airway seal of I-gel has been found to be adequate with chest compressions during cardiopulmonary resuscitation and as a result, an I-gel resuscitation pack has been introduced. ${ }^{21,22}$ We did not find any clinical or volumetric evidence of a leak in surgeries done in Trendelenburg position. I-gel is reported to be as efficient and safe as an ETT during PCV, which is more efficient and safer than VCV with an SAD. 2,23 I-gel has also been used successfully with VCV and for mechanical ventilation lasting for $48 \mathrm{~h}$ with PCV. ${ }^{24,25}$

We used VCV and found its use safe with I-gel, with no evidence of leak in the breathing system. A very small loss of tidal volume was seen in the I-gel group in our study which was statistically insignificant.

The incidence of clinically detectable gastric insufflations and regurgitation with use of SAD, in general, is $0-0.3 \%$ and $0.07 \%$, respectively. The incidence of aspiration with LMAs in fasted patients is $0.012 \%{ }^{26}$ Three cases of regurgitation, including one confirmed gastric aspiration, have been reported with use of I-gel in a study of 280 patients. ${ }^{27} \mathrm{~A}$ meta-analysis of 547 studies on LMAs has however shown that the incidence of pulmonary aspiration with LMA use is uncommon and not higher than that associated with the use of face mask and ETT for day care surgery. ${ }^{28}$ There was no laparoscopic evidence of gastric insufflation, regurgitation, or gastric aspiration in the I-gel group in our study. LMA use has been reported to be associated with lower incidence of complications such as sore throat, cough and difficulty in swallowing as compared to ETT, during low flow VCV. ${ }^{29}$ In our study, we noted complaints of sore throat in two patients in ET group while one patient from I-gel group complained of difficulty in swallowing.

Patients in both groups remained hemodynamically stable throughout the procedure. Changes in peak airway pressures noted during the study were comparable in both groups. Loss of tidal volume was noted in the I-gel group but was statistically insignificant on analysis. Our study had a limitation that both the devices were inserted by a single experienced user and the results may not be replicated by inexperienced users. Further larger studies need to be conducted on I-gel and other second-generation $\mathrm{SAD}$ to establish their efficiency during minimal flow anesthesia.

\section{CONCLUSION}

Based on the results of our study, we conclude that I-gel can be safely and efficiently used during minimal flow anesthesia, with a total FGF of $400 \mathrm{~mL} / \mathrm{min}$, with volume controlled ventilation for laparoscopic surgery of less than two hours duration.

Conflict of interest: None declared by the authors.

Authors' contribution: All authors took part in the conduct of the study, data collection and manuscript preparation. 


\section{REFERENCES}

1. Verghese C, Brimacombe JR. Survey of laryngeal mask airway usage in 11,910 patients: Safety and efficacy for conventional and nonconventional usage. Anesth Analg. 1996;82:129-33. [PubMed] DOl: $\quad 10.1097 / 00000539-$ 199601000-00023

2. Uppal V, Fletcher G, Kinsella J. Comparison of the I-gel with the cuffed tracheal tube during pressure-controlled ventilation. $\mathrm{Br} J$ Anaesth. 2009;102:2648. [PubMed] [FreeFullText] DOI: $10.1093 /$ bja/aen366

3. Singh I, Gupta M, Tandon M. Comparison of Clinical Performance of I-gelTM with LMA - ProsealTM in Elective Surgeries. Indian J Anaesth. 2009;53:302-5. [PubMed] [FreeFullText]

4. Mollhoff T, Burgard G, Prien T. Low flow and minimal flow anesthesia using the laryngeal maskairway. Eur J Anaesthesiol. 1996;13:456-62. [PubMed]_DOI: 10.1046/j.13652346.1996.00988.x

5. Foldes F, Ceravolo A, Carpenter $S$. The administration of nitrous oxide - oxygen anesthesia in closed systems. Ann Surg. 1952; 136:978-81. [FreeFullText] DOl: $\quad 10.1097 / 00000658-$ 195212000-00009

6. Virtue R. Minimal flow nitrous oxide anesthesia. Anesthesiology. 1974;40:196-8 . [PubMed] DOl: 10.1097/00000542-19740200000021

7. Cameron AE, Sievert J, Asbury AJ, Jackson R. Gas leakage and the laryngeal mask airway. A comparison with the tracheal tube and face mask during spontaneous ventilation using a circle breathing system. Anaesthesia.
1996;51:1117-9. [PubMed] [FreeFullText] DOI: $\underline{10.1111 /}$ j.1365-2044.1996.tb15045.x

8. Goyal R, Kapoor MC. Anesthesia: Contributing to pollution? J Anaesthesiol Clin Pharmacol. 2011;27:435-7. DOI: $10.4103 / 0970-9185.86565$

9. Ryan SM, Nielsen CJ. Global warming potential of inhaled anesthetics: application to clinical use. Anesth Analg. 2010;111:92-98. [PubMed] [FreeFullText] DOl: 10.1213/ ANE.0b013e3181e058d7

10. Nunn G. Low-flow anaesthesia. Contin Educ Anaesth Crit Care Pain. 2008; 8:1-4. D0I: 10.1093/ bjaceaccp/mkm052

11. Honemann C, Hagemann O, Doll D. Inhalational anaesthesia with low fresh gas flow. Indian J Anaesth. 2013;57:345-50. [PubMed] [FreeFullText]_DOI: 10.4103/0019$\underline{5049.118569}$

12. Suttner S, Boldt J. Low-flow anaesthesia. Does it have potential pharmacoeconomic c on s e que nces? $\mathrm{Ph}$ armacoe conomics. 2000;17:585-90. [PubMed]_DOI: 10.2165/00019053-200017060$\underline{00004}$

13. Baum J. Low flow anesthesia. Eur J Anaesthesiol. 1996;13:432-5. [PubMed] DOI: 10.1097/00003643-19960900000002

14. Cameron AE, Sievert J, Asbury $A$, Jackson R. Gas leakage and laryngeal mask airway. A comparison with the tracheal tube and face mask during spontaneous ventilation using a circle breathing system. Anaesthesia. 1996:51:1117-9. [PubMed] DOI: 10.1111/i.1365-2044.1996. $\underline{\text { tb15045.x }}$

15. Hönemann CW, Hahnenkamp K, Möllhoff T, Baum JA. Minimalflow anaesthesia with controlled ventilation: comparison between laryngeal mask airway and endotracheal tube. Eur J Anaesthesiol. 2001;18:458-66. [PubMed]_DOI: 10.1046/i.13652346.2001.00868.x

16. Engelhardt T, Johnston G, Kumar MM. Comparison of cuffed, uncuffed tracheal tubes and laryngeal mask airways in low flow pressure controlled ventilation in children. Paediatr Anaesth. 2006;16:140-3. [PubMed]_DOl: 10.1111/i.14609592.2005.01709.x

17. Chauhan G, NayarP, Seth $A$, GuptaK, Panwar M, Agrawal N. Comparison of clinical performance of the I-gel with LMA proseal. J Anaesthesiol Clin Pharmacol. 2013;29:56-60. [PubMed] DOl: 10.4103/0970$\underline{9185.105798}$

18. Shi YB, Zuo MZ, Du XH, Yu Z. Comparison of the efficacy of different types of laryngeal mask airways in patients undergoing laparoscopic gynaecological surgery. Zhonghua Yi Xue Za Zhi. 2013;93:1978-80. [PubMed] [FreeFullText]

19. Mukadder S, Zekine B, Erdogan KG, Ulku O, Muharrem U, Saim $Y$, Mahmut D. The clinical study comparison of the proseal, supreme, and I-gel SAD in gynecological laparoscopic surgeries. Scientific World J. 2015; Vol. 2015:634320. [PubMed] DOI: $10.1155 / 2015 / 634320$

20. Teoh WHL, Lee KM, Suhitharan T, Yahaya Z, Teo MM, Sia ATH. Comparison of the LMA Supreme vs the I-gel ${ }^{\text {TM }}$ in paralysed patients undergoing 
gynaecological laparoscopic surgery with controlled ventilation. Anaesthesia. 2010;65:1173-79. [PubMed] DOl: 10.1111/i.13652044.2010.06534.x

21. Häske D, Schempf B, Gaier G, Niederberger $\mathrm{C}$. Performance of the I-gel $^{\mathrm{TM}}$ during pre-hospital cardiopulmonary resuscitation. Resuscitation. 2013;84:122932. [PubMed] DOI: 10.1016/i. resuscitation.2013.04.025

22. Williams AL, Anderson RM, Nasir MA. In: The I-gel and cardiopulmonary resuscitation. Michalek P, Donaldson W, eds. The I-gel Supraglottic Airway. New York: Nova Science Publishers; 2013. p:151-62.

23. Bordes M, Semjen F, Degryse C, Bourgain JL, Cros AM. Pressure-controlled ventilation is superior to volume-controlled ventilation with a laryngeal mask airway in children. Acta Anaesthesiol Scand. 2007;51:825. [PubMed] DOI: 10.1111/i.13996576.2006.01148.x

24. El-Seify ZA, Khattab AM, Shaaban A, Radojevic D, Jankovic I. Low flow anesthesia: Efficacy and outcome of laryngeal mask airway versus pressure-optimized cuffed-endotracheal tube. Saudi J Anaesth. 2010;4:6-10. [PubMed] DOI: 10.4103/1658-354X.62607

25. Akan B, Erdem D, Albayrak MD, Aksoy E, Akdur F, Gogus N. Pressure support ventilation with the I-gel in intensive care unit: case report. Braz J Anesthesiol. 2016;66:219-22. [PubMed] DOI: 10.1016/i.bjane.2013.10.007

26. Brimacombe J. Laryngeal Mask Anesthesia. Principles and Practice. 2nd Edn. London, UK: WB Saunders; 2004. p:551.

27. Gibbison B, Cook TM, Seller C. Case series: protection from aspiration and failure of protection from aspiration with the I-gel airway. $\mathrm{Br} J$ Anaesth. 2008;100:4157. [PubMed] DOI: 10.1093/bja/ aem396

28. Brimacombe JR, Berry A. The incidence of aspiration associated with the laryngeal mask airway: a meta-analysis of published literature. J Clin Anesth. 1995;7:297-305. [PubMed] DOl: 10.1016/0952-8180(95)00026-e

29. Peirovifar A, Eydi M, Mirinejhad MM, Mahmoodpoor A, Mohammadi A, Golzari SE. Comparison of postoperative complication between Laryngeal Mask Airway and endotracheal tube during lowflow anesthesia with controlled ventilation. Pak J Med Sci. 2013;29:601-5. [PubMed] DOI: 10.12669/pjms.292.2980 